\title{
Shear behaviours of planar unfilled rock discontinuities with reference to surface morphology under constant normal load
}

\author{
Hemant Kumar Singh and Arindam Basu \\ Department of Geology and Geophysics \\ Indian Institute of Technology \\ Kharagpur, India \\ hemant@gg.iitkgp.ernet.in
}

\begin{abstract}
Stability of rock masses at shallow depth is often controlled by shear behavior of discontinuities. This is an important issue in an engineering environment as well as from societal point of view. With regard to shear behavior assessment through laboratory investigation, direct shear test under constant normal load were carried out on two types of rock such that joint in granite and sandstone bedding planes. From each rock types three samples of similar joint roughness coefficient (varied between 0.86-1.52) were selected for investigation. It should be noted that same sample was tested thrice at three different consecutively increasing low normal stresses (ranges: 0.22-0.23 MPa, 0.45-0.46 MPa and 0.69-0.70 MPa respectively). At low normal stresses (0.22-0.23 MPa), three types of shear behavioral characteristics of natural rock discontinuity (i.e. for both types of rock) were observed whereas at relatively higher normal stresses $(0.45-0.70 \mathrm{MPa})$, shear behaviors along these discontinuities plane were found to be broadly similar. In general, the differences of peak shear strengths and peak shear displacement increases as applied normal stress increases with subsequent stages of shearing. The probable reason behind individuality of results was explained.
\end{abstract}

Keywords-shear behavior of discontinuity; surface morphology; joint roughness coefficient; peak shear strength; joint in granite; sandstone bedding plane.

\section{INTRODUCTION}

Rock failure within rock masses commonly occurs along weak planes/discontinuities (e.g. joints, faults, bedding planes, foliations, etc.) in shear mode in-situ under constant normal load condition because of low stresses at shallow depth [1]. This is an important issue in an engineering environment as well as from societal point of view. With regard to shear strength assessment through laboratory investigation, direct shear test under constant normal load got significant attention. Over the years, a number of researchers explored rock discontinuity shear behaviors under constant normal load through laboratory investigation with reference to different aspects like joint roughness coefficient, surface morphology, joint compressive strength, normal stress, fluid conditions, scale effect and shearing rate [2-8]. They studied this issue considering either mimicked or tensional rock discontinuities. Few studies focused on interlocked joints with matching plane of contact [9]. However, it is often observed that contact planes of a natural rock joint have dissimilar roughness characteristics near shallow depth, in other word, the un-matching planes of contact are often observed at shallow depth because of preferential weathering and subsequent erosion of surface asperities of discontinuity due to movements of various fluids in situ [1, 10]. It is obvious from the previous study, few researchers have explored shear behavior issue of unmatching rough rock discontinuity through laboratory investigation using mimicked/replica discontinuity. However, the investigation of shear behavior of planar natural rock discontinuity with reference to surface morphology and without infilling material does not seem to have gained much attention. This paper aims to explore the said issue through laboratory investigation of planar unfilled rock discontinuity in Singhbhum Granite (in the state of Odisha, India) and Mungra Sandstone (in the state of Jharkhand, India) respectively.

It is evident from many studies that surface morphology is effective only at low normal stress whereas its effect is negligible at high normal stress [1-2, 4, 6-7]. For laboratory investigation, Kulatilake et al. [11] indicated that a normal stress $\leq 1 \mathrm{MPa}$ can be considered as a low normal stress. The present study involves direct shear test on natural planar unfilled rock discontinuity under constant low normal stress. It should be noted that individual samples undergo shearing for three times in a particular direction (same as the dip direction of the discontinuities in-situ), at three consecutively increasing low normal stresses.

\section{EXPERIMENTAL STUDIES}

\section{A. Collection of Discontinuity Samples}

Two rocks types of discontinuities were consider for present investigation such as joints in granite and sandstone bedding planes. The jointed granite samples were collected

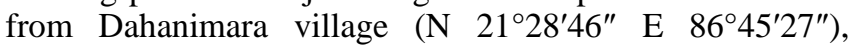
Balasore District, Odisha. This area is positioned $28 \mathrm{Kms}$ towards SW from nearby railway station (Balasore). The exposure from where samples were collected (Fig.1A) is located within peripheral parts of the Singhbhum Granite, 

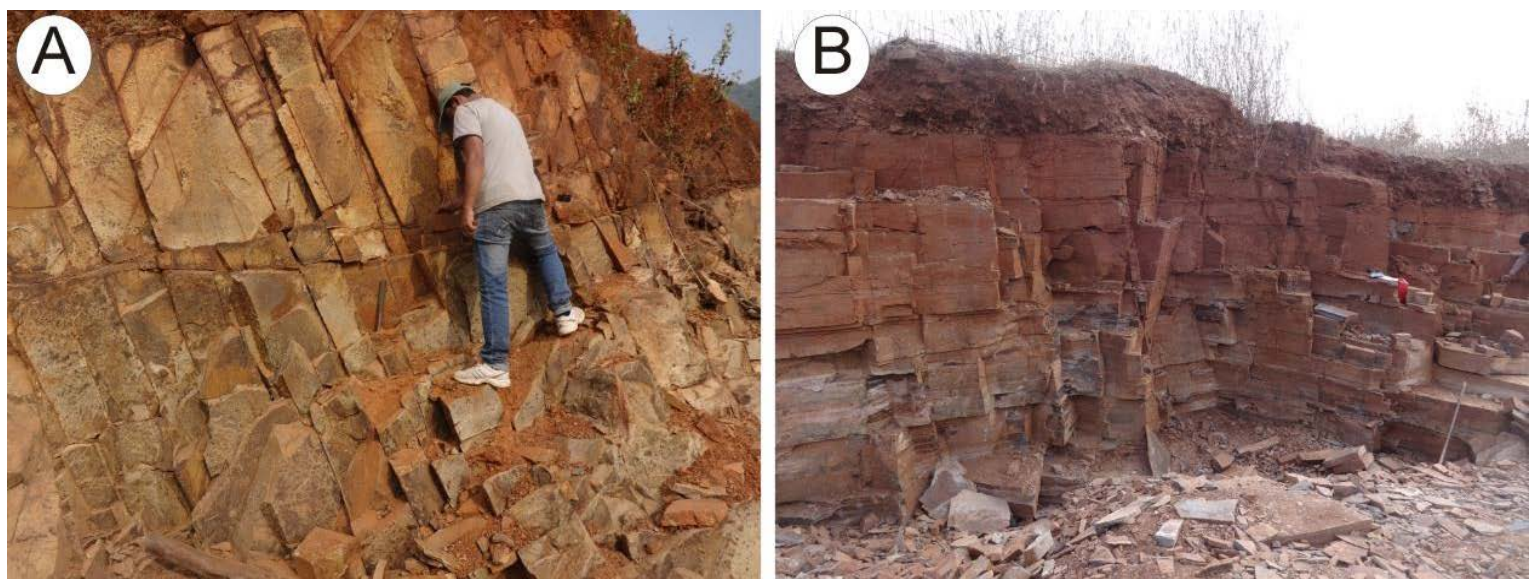

Fig.1 An example of exposure from where samples were collected for, (A) granite and, (B) sandstone

Sandstone block samples, containing bedding planes, were collected from an exposure Fig.1B) in Jhinkpani near Chaibasa town, Jharkhand state of India. Geologically, this area belongs to Mungra sandstone formation (thickness $\sim 25 \mathrm{~m}$ ) of Kolhan Group which is underlain by basal conglomerate and overlain by Jhinkapani limestone [13-14]. The age of Mungra sandstone is around $1 \mathrm{Ga}$ [14]. The discontinuity of the collected samples showed dissimilar degrees of decomposition. In order to eliminate varying degree of weathering grade on the rock discontinuity shear behaviors, samples only with slightly discolored discontinuity surface (in compliance with [15-16] depth of discolored part $\approx 1 \mathrm{~mm}$ ) having a similar rebound hammer value ranges 41 - 49 for granite \& 45-52 for sandstone) were selected, arbitrarily numbered and transported for laboratory investigation.

\section{B. Selection of Discontinuity Samples}

The Schmidt rebound value measure on the surface of discontinuities in-situ for each weakness plane was normalized in the horizontal direction as indicated in Basu and Aydin [17]. ISRM [16] suggested method was followed to measure total dry density of sample in the laboratory. The joint compressive strength (JCS) was estimated by using the empirical formula proposed by Deere and Miller [18], for each samples. Samples having JCS values (JCS: ranges 100118, 165-170 for granite 5-7 mm for each half of the block) from encapsulating material. The samples were airdried over 23-28 days.

\section{Determination of Joint Roughness Coefficient (JRC)}

The fractal dimension method was used to quantify JRC in the present investigation, because of its simplicity, accuracy and growing acceptance amongst researcher in the field of rock engineering environment $[1,20]$ It's clear from the existing literature, many fractal dimension techniques/method are existed such as Compass walking method, modified divider method, Box counting method and H-L method. However, modified divider method is simple to use and measured accurately as indicated in Sanei et al.
[20]. In the present study, the modified divider method technique was utilized to estimate fractal dimension of discontinuity surface's profiles (measured by needle type profilometer attached with digital dial gauge (resolution $0.01 \mathrm{~mm})$ ). The theory of modified divider method is to split profile length of rock discontinuity with equal straight divider span and subsequent measurement of each divider span (Fig.2A). The estimation of fractal dimension of the profiles was done by following equation (1) (as in Sanei et al.[20]).

$$
\log L(r)=\log a+(1-D) \log r
$$

where 'L(r)', 'a', 'r'and 'D' are total length of the profile, proportionality constant, divider span and fractal dimension respectively. The fractal dimension was estimated from the slope of the graph (plotted as log L(r) vs. log r) (Fig.2 (B)). It should be noted that the newly written code for divider method was used to estimate fractal dimension in which divider span ranges 0.5-6 mm.

\section{Sample Preparation for Direct Shear Test}

The selected samples were encapsulated with the help of sand and cement mixture (sand-cement mixture ratio (by volume): 3:1) and optimum amount of water required for hardening was used as the casting material. It is to note that the encapsulation was done in such a way that the possible shear direction remains parallel to the dip direction of the concerned where ' $L(r)$ ', ' $a$ ', ' $r$ ' and ' $D$ ' are total length of the profile, proportionality constant, divider span and fractal dimension respectively. The fractal dimension was estimated from the slope of the graph (plotted as $\log \mathrm{L}(\mathrm{r}) \mathrm{vs}$. $\log$ r) (Fig.2 (B)). It should be noted that the newly written code for divider method was used to estimate fractal dimension in which divider span ranges 0.5-6 mm. The measured surface profiles data of the discontinuity were used as an input file for this program to acquire the fractal dimension value. Afterward, the empirical formula proposed by Sanei et al. [20] as shown in equation (2), was used to determine JRC values of discontinuity profiles JRC values

$$
\text { JRC } \quad 37580 D^{2} \quad 77018 D \quad 39438
$$




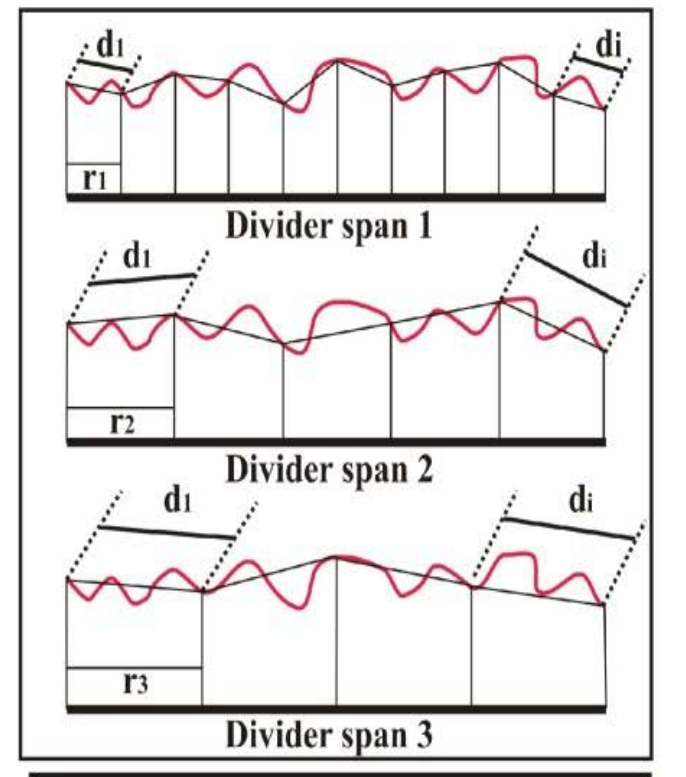

$$
L(r)=\left[\left\{\sum_{i=1}^{N} d_{i}(r)\right\}+d_{r}\right]
$$

Fig.2 (A) Various divider spans applied for profile (B) The log L(r) - log r plot.

\section{E. Test Setup and Procedure}

The fabricated mechanical profilometer (contact type profilometer, resolution $0.01 \mathrm{~mm}$ ), as shown in Fig.3A, was used to record the surface asperities height of each block of a shear test sample. To record surface asperities height of discontinuity plane, initially the discontinuity surface was divided into grids $(0.5 \mathrm{~mm}$ interval) with help of water marker and afterwards, the dial gauge was moved by hand along parallel to shear direction. Whole data of asperities height were recorded by data acquisition system in excel sheet. To cover surface asperities height of discontinuity, this process was repeated for whole surface. Same procedure was used to cover asperities height for each block. In this investigation, sampling interval was interpolated for the whole surface at $0.5 \mathrm{~mm}$ interval using linear interpolation technique (Singh and Basu 2016).

The present investigation was carried out under constant normal load condition using a laboratory direct shear test apparatus (AIM 221 ${ }^{\circ}$ ) with $100 \mathrm{kN}$ load capacity (i.e. for shear load as well as for normal load) as shown in Fig. 3B. This system (DST) is attached with two vertical and two horizontal displacement sensors (measuring range: 25 and $12.5 \mathrm{~mm}$; resolution: $0.01 \mathrm{~mm}$ ) respectively (Fig.3B). While performing the shear tests (rate of shearing $\approx 0.2-0.5$ $\mathrm{mm} / \mathrm{min}$ ), normal stresses were kept constant within a range of 0.22-0.23 $\mathrm{MPa}$, 0.45-0.46 $\mathrm{MPa}$ and 0.69-0.70 $\mathrm{MPa}$ respectively. Applied shear load was recorded with reference to an interval of $0.5 \mathrm{~mm}$ displacement until the applied load becomes steady and independent of displacement. It is to note that same sample was tested thrice at three consecutively increasing low normal stresses along parallel to dip direction in-situ. The measurement of each of normal and shear displacements was done using two digital dial gauges to obtain averaged values.
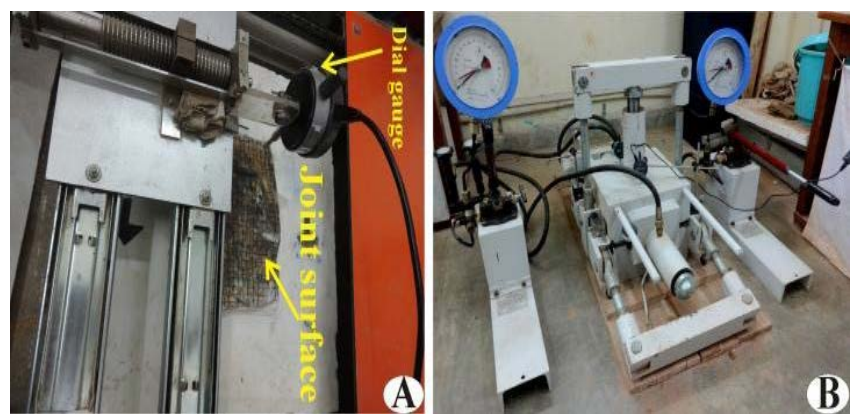

Fig.3 (A) Prepared shear test sample along with the needle type contact profilometer (B) Laboratory setup for direct shear test.

\section{EXPERIMENTAL RESULT AND ANALYSIS}

Direct shear tests were carried out on 6 natural planar discontinuities samples (i.e. three samples for each rock types) at three different consecutively increasing normal stresses ranges 0.22-0.23 $\mathrm{MPa}, 0.45-0.46 \mathrm{MPa}$ and 0.69$0.70 \mathrm{MPa}$ respectively. The primarily results of the entire investigation i.e. assessment of shear behavioral characteristics of discontinuity plane, influence of surface morphology on peak shear strength and displacement and differences in peak shear with stages of shearing were present in Figs. 4 and 5 and Table-I respectively. 

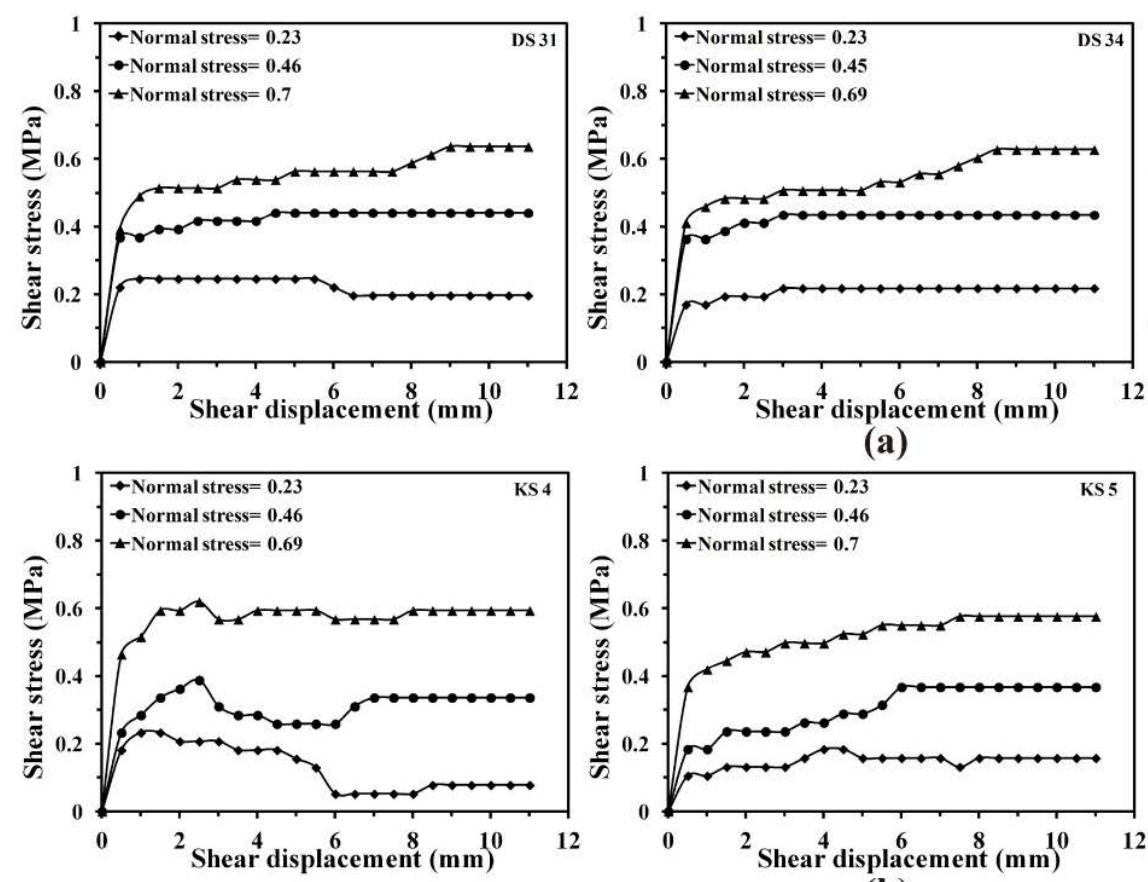

(a)

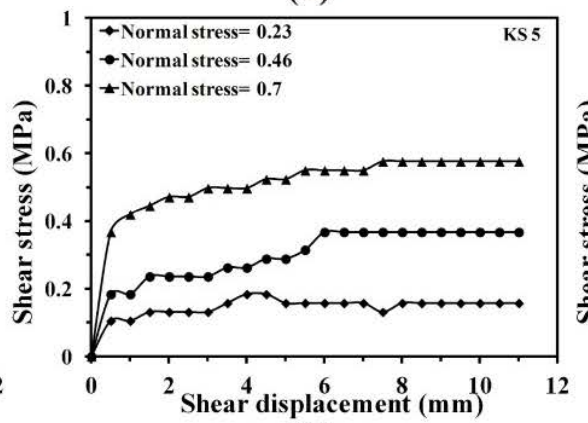

(b)
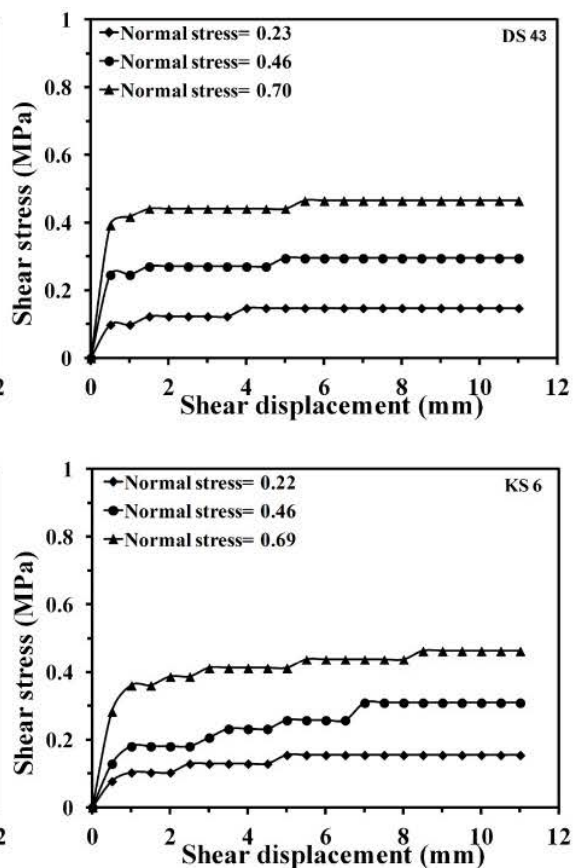

Fig.4 Shear stress- shear displacement curves for the tested samples of (a) granite and (b) sandstone

\section{A. Assessment of Shear Behavioural Characteristics of Discontinuity Plane}

The shear tests were performed on 6 different discontinuity planes at three different consecutively increasing low normal stresses ranging $0.22-0.23,0.45-0.46$ and $0.69-0.70$ $\mathrm{MPa}$ respectively. Subsequently, the shear stress- shear displacement/ horizontal displacement was plotted for all samples as shown in Fig. 4 and Table 1. It is evident from Fig.4; in general, three types of curve pattern were observed at normal stresses ranges $0.22-0.23$ such that

(a) increase in shear stress followed by constant against horizontal displacement (up to $5.5 \mathrm{~mm}$ ) subsequently, followed by slightly fall of shear stress against shear displacement (DS 31). It is attributed by oversliding of asperities up to some limit and followed by slightly/minor breakage in asperities during shearing on the plane of contact of discontinuity.

(b) Continuous increase in shear stress is followed by fall against horizontal displacement (e.g. KS-4 and KS-5). It is possible because of overriding and subsequent minor breakage of asperities on the plane of contact during the movement. (c) Shear stress increases with displacement over some limit and subsequently followed by alternative rise and constant (DS 34, DS 43 and KS 6). This might be possible because of alternative overriding and oversliding of asperities on the plane of contact during shearing. In other words, during shearing, if asperities within a contact zone are damaged, there may be a possibility that asperities of a subsequent zone would resist the movement of one block with reference to the other and thereby would prompt the experimentalist to increase the shear stress further Fig. 4.

It is obvious from Fig.4 (for stage 2 \& 3), the shear behavioral characteristics are to be found broadly similar as the consecutive stages of shearing increase with successive increment in normal stress for all samples except KS 4. It is attributed that the surface morphology is more effective at lower normal stresses compare to relatively higher normal stresses. In other words, at low normal stress (ranges 0.220.23 ), different types of shear behavioral curve pattern are found (Fig. 4) because two types of asperities (primary as well as secondary) are affecting together on contact zone during shearing whereas at relatively higher normal stress $(\leq 0.7)$, effect of secondary asperities dismisses due to damages and smoothening of asperities during movement.

\section{B. Influence of surface morphology on peak shear strength and displacement}

Fig. 4 and Table I indicates that peak shear strength of different samples is varied significantly even though JRCs of all samples are similar at different stages shearing (ranges: 0.22-0.23 MPa; 0.45-0.46 MPa and 0.69-0.70 MPa. This results signifies that the peak shear strength is mainly controlled by contact area and surface morphology. The plot (Fig.5) of differences in peak shear strength with stages of shearing at consecutively increasing normal stresses (varied between (0.23-0.7 MPa)) depict that differences in peak shear strength are increases with successive increment in normal stress which indicates that influence of primary asperities and contact area is more dominant at relatively higher normal stress. These results contradict the existing concept in literature [2, 4, 6-7]. The explanation of this discrepancy could be explained in following manner: Stages of shearing leads to continuous increase in contact area, grains-grains interlocking and activation of primary asperities as results differences in peak shear is more at higher stress compare to lower stress. 
The peak shear displacement varied within a range of 15, 2.5-7 and 2.5-9 mm respectively. This range of displacement is significantly larger than the same in the existing literature [2, 9, 20-22]. Where shearing along a mimicked discontinuity (surface made up of a different material) or along an artificial/interlocked. Rock discontinuity with same surface roughness of the contact planes at similar normal loads was involved. This might be possible due to differences in the degree of over sliding of asperities on plane of contact

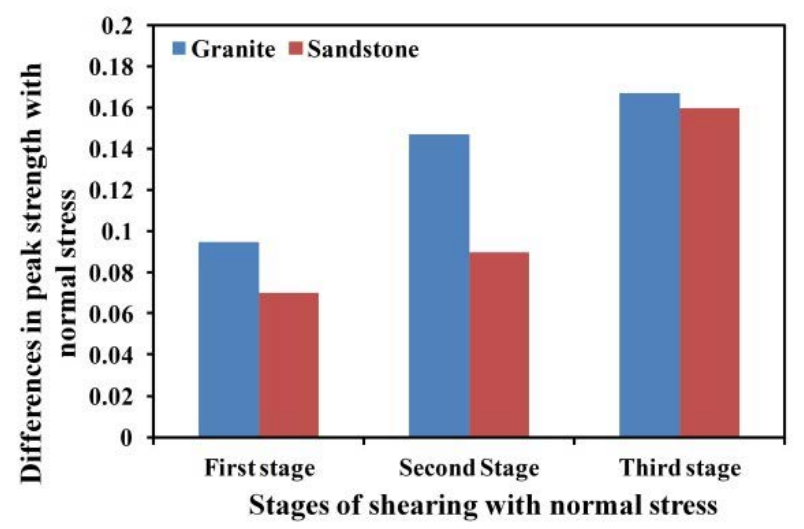

Fig. 5 Plot of differences in peak shear strength with stages of shearing at consecutively increasing normal stresses

TABLE I EXPERIMENTAL RESULT OF SHEAR TEST

\begin{tabular}{|c|c|c|c|c|}
\hline S.N. & JRC & $\sigma_{\mathbf{n}}(\mathrm{MPa})$ & $\tau_{p}(\mathbf{M P a})$ & $\delta_{\mathbf{h}}(\mathrm{mm})$ \\
\hline \multirow{3}{*}{ DS 31} & \multirow{3}{*}{1.54} & 0.23 & 0.25 & 1 \\
\hline & & 0.46 & 0.44 & 4.5 \\
\hline & & 0.7 & 0.64 & 9 \\
\hline \multirow{3}{*}{ DS 34} & \multirow{3}{*}{0.86} & 0.23 & 0.22 & 3 \\
\hline & & 0.45 & 0.44 & 3 \\
\hline & & 0.69 & 0.63 & 9 \\
\hline \multirow{3}{*}{ DS 43} & \multirow{3}{*}{1.7} & 0.23 & 0.15 & 4 \\
\hline & & 0.46 & 0.29 & 5 \\
\hline & & 0.7 & 0.47 & 5.5 \\
\hline \multirow{3}{*}{ KS 4} & \multirow{3}{*}{1.85} & 0.23 & 0.232 & 1 \\
\hline & & 0.45 & 0.39 & 2.5 \\
\hline & & 0.69 & 0.62 & 2.5 \\
\hline \multirow{3}{*}{ KS 5} & \multirow{3}{*}{1.47} & 0.23 & 0.18 & 4 \\
\hline & & 0.46 & 0.37 & 6 \\
\hline & & 0.7 & 0.58 & 7.5 \\
\hline \multirow{3}{*}{ KS 6} & \multirow{3}{*}{1.52} & 0.22 & 0.16 & 5 \\
\hline & & 0.46 & 0.31 & 7 \\
\hline & & 0.69 & 0.46 & 8.5 \\
\hline
\end{tabular}

Note: $\sigma_{\mathrm{n}}=$ Normal stress; $\tau_{\mathrm{p}}=$ Peak shear strength; $\delta_{\mathrm{h}}=$ Shear

displacement; JRC = Joint roughness coefficient

\section{CONCLUSIONS}

The direct shear tests on the six concerned discontinuity samples with very similar JRC were performed in the laboratory at three different consecutively increasing normal stresses ranges 0.22-0.23 $\mathrm{MPa}, 0$. 44-0.46 $\mathrm{MPa}$, and 0.68$0.70 \mathrm{MPa}$ respectively. From the primarily results of above investigation the following concluding remarks are drawn:

- At low normal stresses three types of shear behavioral characteristics were observed whereas at relatively increasing normal stresses, shear behaviors of these joints were found to be broadly similar. This indicated that surface morphology is showing superseding effect on contact area and textural interlocking at low normal stress than relatively higher normal stresses. This could be possible in following way: at low normal stresses two types of asperities (primary as well as secondary) are affecting together on contact zone during shearing whereas at relatively higher normal stress $(\leq 0.7)$, effect of secondary asperities dismisses due to damages and smoothening of asperities during movement as results at relatively higher normal stress similar types of curve patterns were observed.

- The differences of peak shear strength increases with stages of shearing except third stage. This may be maybe explained in following manner: stages of shearing leads to increase in contact area as well as interlocking of grains compare to previous low normal stages. This leads to increase in differences of shear strength compare to previous stage.

- The peak shear displacement varied within a range of 16.5, 3-7 and 4-9 $\mathrm{mm}$ respectively. This range of displacement is significantly larger than the same in the existing literature where shearing along a mimicked joint surface made up of a different material or along a artificial or interlocked rock discontinuity with same surface roughness of the contact planes at similar normal loads was involved. This could also be attributed to overriding and over sliding of asperities of the contact planes of 'real' (i.e. not mimicked/fabricated) natural joints.

\section{ACKNOWLEDGMENT}

Support of Indian Institute of Technology, Kharagpur, is gratefully acknowledged.

\section{REFERENCES}

[1] H. K. Singh and A. Basu, "Shear behaviors of ' real ' natural unmatching joints of granite with equivalent joint roughness coef fi cients,” Eng. Geol., vol. 211, pp. 120-134, 2016.

[2] N. Barton, "Range of normal stress The most important factor in the shear strength of a rock joint is the," vol. 7, pp. 287-332, 1973.

[3] N. Barton and V. Choubey, "The shear strength of rock joints in theory and practice,” Rock Mech., vol. 10, no. 1-2, pp. 1-54, 1977.

[4] N. Barton and S. Bandis, "Some effects of scale on shear strength of rock joints,” Int. J. Rock Mech. Min. Sci. Geomech. Abstr., 1980.

[5] T. Belem, F. Homand-Etienne, and M. Souley, "Quantitative Parameters for Rock Joint Surface Roughness,” Rock Mech. Rock Eng., vol. 33, no. 4, pp. 217-242, 2000.

[6] G. Grasselli and P. Egger, "Constitutive law for the shear strength of rock joints based on three-dimensional surface parameters,” Int. J. Rock Mech. Min. Sci., vol. 40, no. 1, pp. 25-40, 2003.

[7] J. Hu, D. Ruan, X. Luo, and K. Zhou, "Morphology characteristics of joint surface in rock mass,” J. Cent. South Univ., vol. 19, no. 10, pp. 2918-2925, 2012. 
[8] A. Usefzadeh, H. Yousefzadeh, H. Salari-rad, and M. Sharifzadeh, "Empirical and mathematical formulation of the shear behavior of rock joints,” Eng. Geol., vol. 164, pp. 243-252, 2013.

[9] W. Li, J. Bai, J. Cheng, S. Peng, and H. Liu, "Determination of coalrock interface strength by laboratory direct shear tests under constant normal load,” Int. J. Rock Mech. Min. Sci., vol. 77, pp. 60-67, 2015.

[10] H.K. Singh, and A. Basu "Influence of surface roughness characteristics of unfilled rock joints on shear behaviors,” J. of EG., Special Pub.,pp.246-254, 2015.

[11] Y. Ge, P. H. S. W. Kulatilake, G. Shou, T.H. Huang, and R.M. Morgan, "New Peak Shear Strength Criteria for Anisotropic Rock Joints,” Int. J. Rock Mech. Min. Sci. Geomech. Abstr., vol. 32, no. 7, pp. 673-697, 1995.

[12] S. N. Sarkar, and A.K. Saha, "The present status of the Precambrian stratigraphy, tectonics and geochronology of Singhbhum-KeonjharMayurbhanj region, eastern India,”Ind. J Earth Sci.,4, pp. 37-65, 1977.

[13] S.P. Singh, " Precambrian Stratigraphy of Bihar - An Overview," In:B. S. Paliwal (Editor), The Indian Precambrian. Scientific Publishers, Jodhpur, India, pp. 376-408, 1998.

[14] J. Mukhopadhyay, G. Ghosh, A. K. Nandi, and A. K. Chaudhuri, "Depositional setting of the Kolhan Group: Its implications for the development of a Meso to Neoproterozoic deep-water basin on the south Indian craton,” South African J. Geol., vol. 109, no. 1-2, pp. 183-192, 2006.

[15] ANON, " The description and classification of weathered rocks for engineering purposes,"Geological Society Engineering Group Working Party Report, Q. J. Eng. Geol., vol. 28, pp. 207-242, 1995.

[16] R. Ulusay, "The Complete ISRM Suggested Methods for Rock Characterization, Testing and Monitoring:" 1974-2006., 2007.

[17] A. Basu and A. Aydin, "A method for normalization of Schmidt hammer rebound values,” Int. J. Rock Mech. Min. Sci., vol. 41, pp. 1211-1214, 2004.

[18] D. U. Deere and R. Miller, "Engineering classification and index properties for intact rock,” Tech. Report, Air Force Weapons Lab., vol. 1, pp. 65-116, 1966.

[19] J. Muralha, G. Grasselli, B. Tatone, M. Blümel, P. Chryssanthakis, and J. Yujing, "ISRM Suggested Method for Laboratory Determination of the Shear Strength of Rock Joints: Revised Version,” Rock Mech. Rock Eng., vol. 47, no. 1, pp. 291-302, 2014.

[20] M. Sanei, L. Faramarzi, A. Fahimifar, S. Goli, A. Mehinrad, and A. Rahmati, "International Journal of Rock Mechanics \& Mining Sciences Shear strength of discontinuities in sedimentary rock masses based on direct shear tests,” Int. J. Rock Mech. Min. Sci., vol. 75, pp. 119-131, 2015.

[21] F. Johansson, "Shear Strength of Unfilled and Rough Rock Joints in Sliding Stability Analyses of Concrete Dams,” p. 200, 2009.

[22] J. W. Park and J. J. Song, "Numerical method for the determination of contact areas of a rock joint under normal and shear loads," Int. J. Rock Mech. Min. Sci., vol. 58, pp. 8-22, 2013. 